Supporting Information

\title{
Tuning the Structure and Chiroptical Properties of Gold Nanoparticle Single Helices via Peptide Sequence Variation
}

\author{
Soumitra Mokashi-Punekar, ${ }^{\dagger}$ Tiffany R. Walsh, ${ }^{*, \nabla}$ and Nathaniel L. Rosi ${ }^{*, \dagger, \dagger}$ \\ †Department of Chemistry, University of Pittsburgh, Pittsburgh, Pennsylvania 15260, United States \\ ${ }^{\nabla}$ Institute for Frontier Materials, Deakin University, Geelong, Victoria 3216, Australia \\ tDepartment of Chemical and Petroleum Engineering, University of Pittsburgh, Pennsylvania 15260, \\ United States
}




\section{Mass spectrometry characterization of peptides}
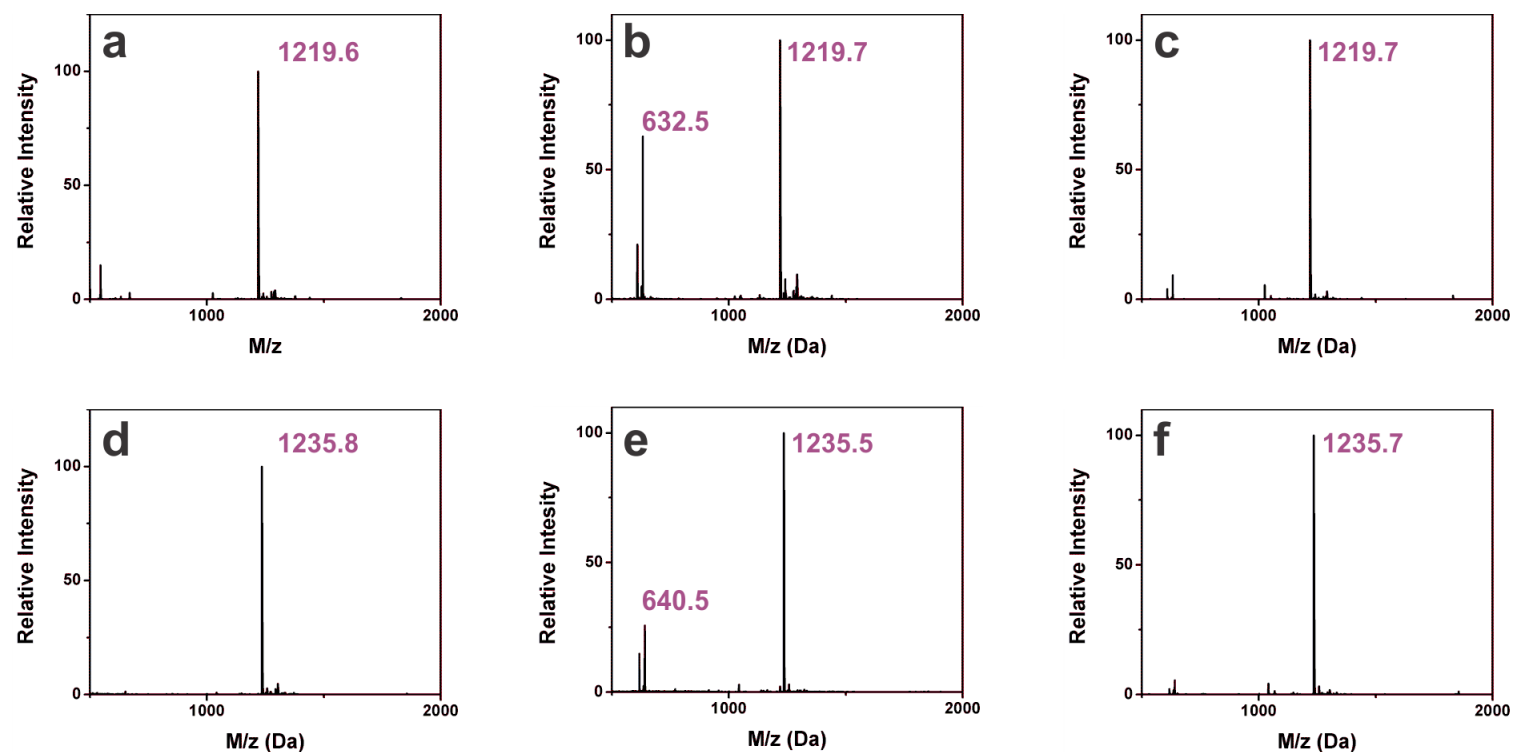

Figure S1. LC-MS assignment of (a) $\mathrm{PEP}_{\mathrm{Au}}^{\mathrm{M}, 7}=1219.6 \mathrm{Da}\left(\mathrm{M}-\mathrm{H}^{+}\right)$; (b) $\mathrm{PEP}_{\mathrm{Au}}{ }^{\mathrm{M}, 9}=1219.6 \mathrm{Da}$ $\left(\mathrm{M}-\mathrm{H}^{+}\right), 632.5\left(\mathrm{M}-2 \mathrm{H}^{+}\right) / 2$; (c) $\mathrm{PEP}_{\mathrm{Au}}^{\mathrm{M}, 11}=1219.7 \mathrm{Da}\left(\mathrm{M}^{+} \mathrm{H}^{+}\right)$; (d) $\mathrm{PEP}_{\mathrm{Au}}^{\mathrm{M}-\mathrm{ox}, 7}=1235.8 \mathrm{Da}(\mathrm{M}-$ $\left.\mathrm{H}^{+}\right)$; (e) $\mathrm{PEP}_{\mathrm{Au}}{ }^{\mathrm{M}-\mathrm{ox}, 9}=1235.5 \mathrm{Da}\left(\mathrm{M}-\mathrm{H}^{+}\right), 640.5 \mathrm{Da}\left(\mathrm{M}-2 \mathrm{H}^{+}\right) / 2$; (f) $\mathrm{PEP}_{\mathrm{Au}}{ }^{\mathrm{M}-\mathrm{ox}, 11}=1235.7 \mathrm{Da}(\mathrm{M}-$ $\left.\mathrm{H}^{+}\right)$. 


\section{Mass spectrometry characterization of peptide conjugates}
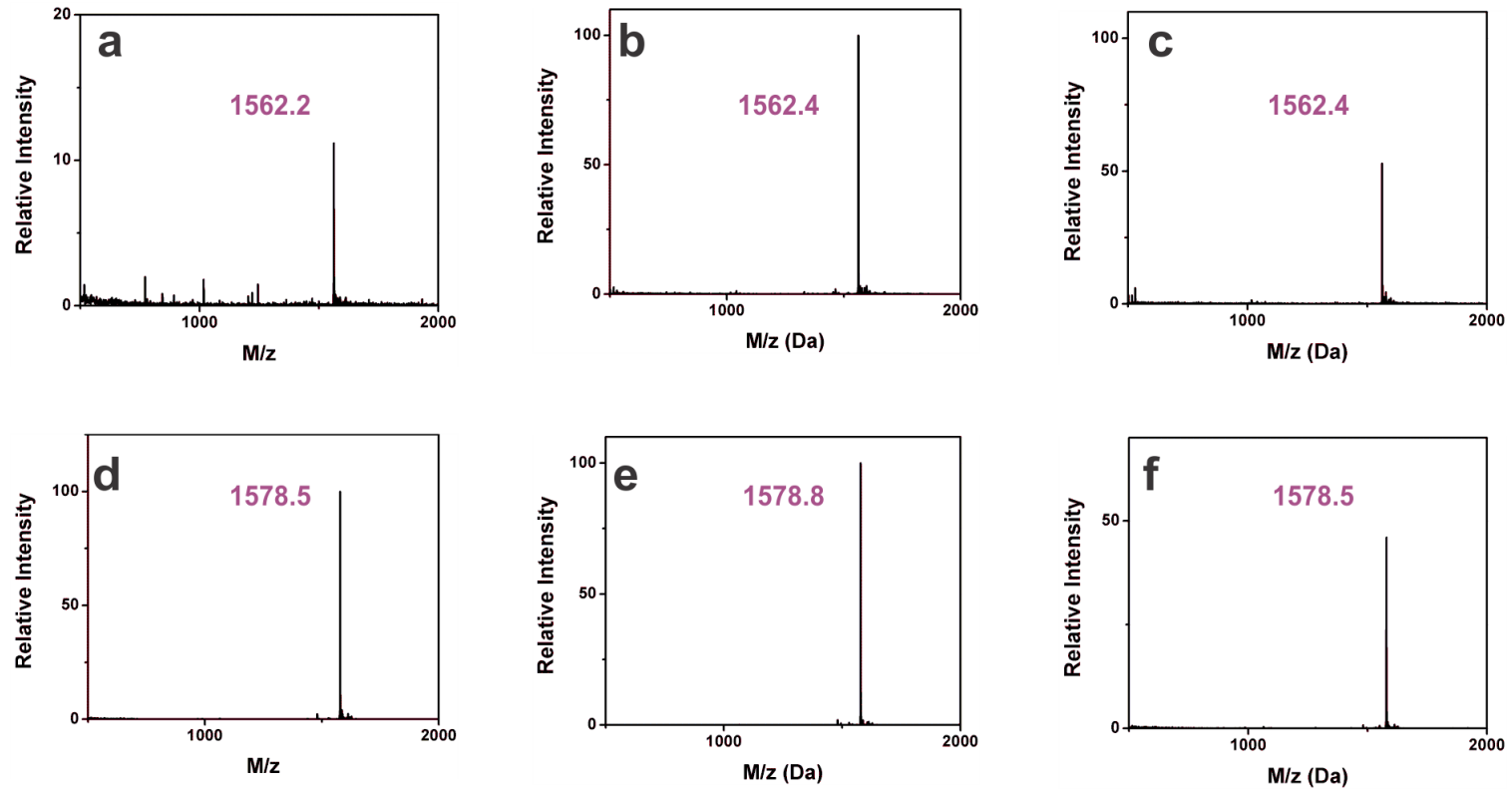

Figure S2. LC-MS assignment of (a) $\mathrm{C}_{18}-\left(\mathrm{PEP}_{\mathrm{Au}}^{\mathrm{M}, 7}\right)_{2}=1562.2 \mathrm{Da}\left(\mathrm{M}-2 \mathrm{H}^{+}\right) / 2$; (b) $\mathrm{C}_{18^{-}}$ $\left(\mathrm{PEP}_{\mathrm{Au}}^{\mathrm{M}, 9}\right)_{2}=1562.4 \mathrm{Da}\left(\mathrm{M}-2 \mathrm{H}^{+}\right) / 2 ;$ (c) $\mathrm{C}_{18}-\left(\mathrm{PEP}_{\mathrm{Au}}^{\mathrm{M}, 11}\right)_{2}=1219.7 \mathrm{Da}\left(\mathrm{M}-2 \mathrm{H}^{+}\right) / 2 ;$ (d) $\mathrm{C}_{18^{-}}$ $\left(\mathrm{PEP}_{\mathrm{Au}}{ }^{\mathrm{M}-\mathrm{ox}, 7}\right)_{2}=1578.5 \mathrm{Da}\left(\mathrm{M}-2 \mathrm{H}^{+}\right) / 2 ;(\mathrm{e}) \mathrm{C}_{18}\left(\mathrm{PEP}_{\mathrm{Au}}{ }^{\mathrm{M}-\mathrm{ox}, 9}\right)_{2}=1578.8 \mathrm{Da}\left(\mathrm{M}-2 \mathrm{H}^{+}\right) / 2$; (f) $\mathrm{C}_{18^{-}}$ $\left(\mathrm{PEP}_{\mathrm{Au}}^{\mathrm{M}-\mathrm{ox}, 11}\right)_{2}=1578.5 \mathrm{Da}\left(\mathrm{M}-2 \mathrm{H}^{+}\right) / 2$. 
UV-vis absorption spectra of AuNPs synthesized in the presence of peptides

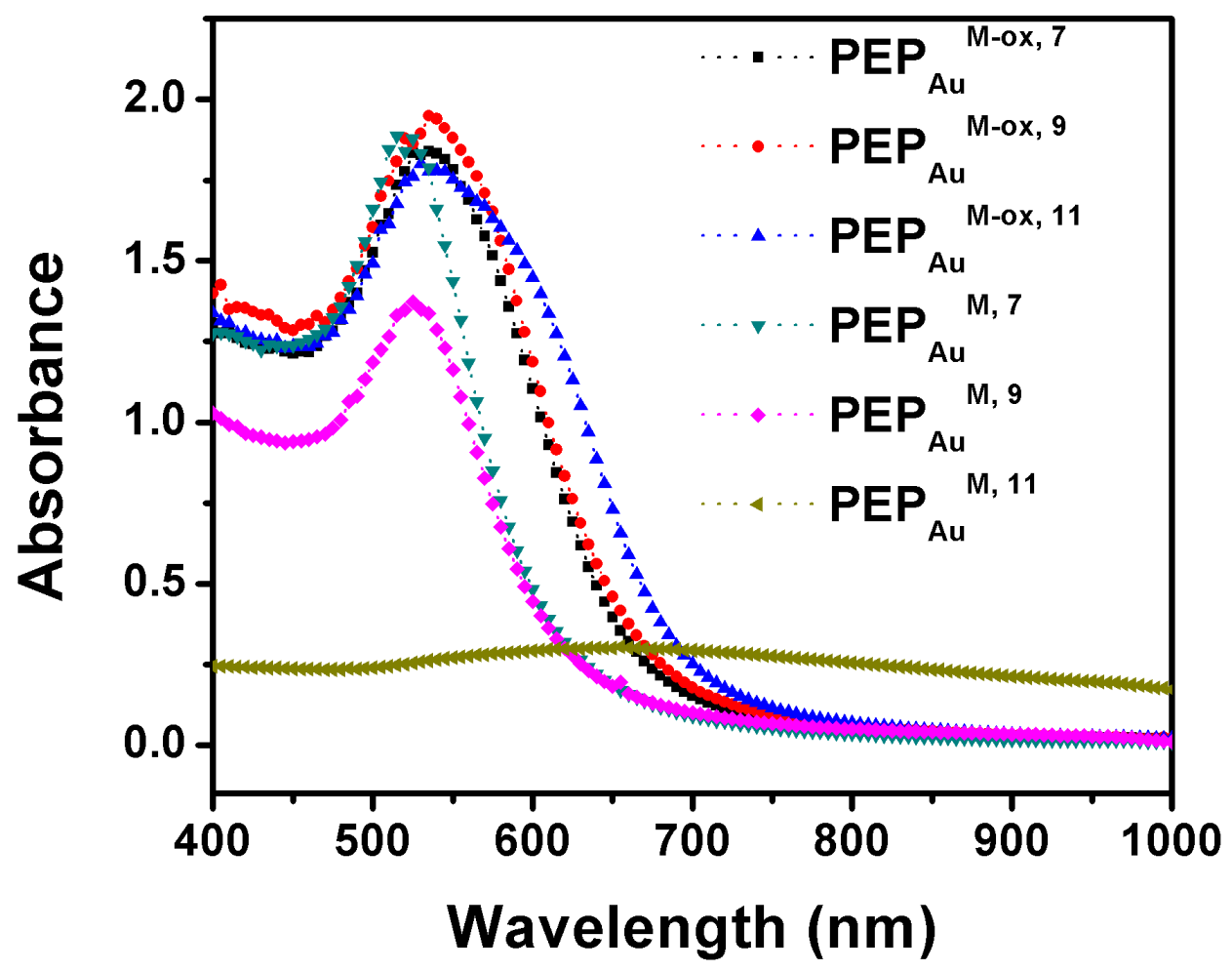

Figure S3. UV-vis absorption spectra of AuNPs synthesized in the presence of methionine-based variant peptides. Slight shifts in peak maxima and peak broadening observed in the case of peptides containing M-ox is consistent with their larger AuNP size. 


\section{Conformational ensemble distribution for peptides in the unadsorbed state}

Table S1. Conformational ensemble population distribution for the top ten most populated distinct structures (clusters) of PEP ${ }_{\mathrm{Au}}^{\mathrm{M}, 9}$ (AYSSGAPPMPPF) in the unadsorbed state.

\begin{tabular}{|c|c|}
\hline $\begin{array}{c}\text { Cluster } \\
\text { rank }\end{array}$ & $\begin{array}{c}\text { Percentage } \\
\text { population }\end{array}$ \\
\hline 1 & 22 \\
\hline 2 & 7 \\
\hline 3 & 6 \\
\hline 4 & 5 \\
\hline 5 & 4 \\
\hline 6 & 3 \\
\hline 7 & 3 \\
\hline 8 & 2 \\
\hline 9 & 2 \\
\hline 10 & 2 \\
\hline
\end{tabular}

Table S2. Conformational ensemble population distribution for the top ten most populated distinct structures (clusters) of $\mathrm{PEP}_{\mathrm{Au}}{ }^{\mathrm{M}, 7}$ (AYSSGAMPPPPF) in the unadsorbed state.

\begin{tabular}{|c|c|}
\hline $\begin{array}{c}\text { Cluster } \\
\text { rank }\end{array}$ & $\begin{array}{c}\text { Percentage } \\
\text { population }\end{array}$ \\
\hline 1 & 10 \\
\hline 2 & 8 \\
\hline 3 & 8 \\
\hline 4 & 7 \\
\hline 5 & 5 \\
\hline 6 & 4 \\
\hline 7 & 4 \\
\hline 8 & 3 \\
\hline 9 & 3 \\
\hline 10 & 3 \\
\hline
\end{tabular}


Table S3. Conformational ensemble population distribution for the top ten most populated distinct structures (clusters) of $\mathrm{PEP}_{\mathrm{Au}}^{\mathrm{M}, 11}$ (AYSSGAPPPPMF) in the unadsorbed state.

\begin{tabular}{|c|c|}
\hline $\begin{array}{c}\text { Cluster } \\
\text { rank }\end{array}$ & $\begin{array}{c}\text { Percentage } \\
\text { population }\end{array}$ \\
\hline 1 & 12 \\
\hline 2 & 10 \\
\hline 3 & 8 \\
\hline 4 & 6 \\
\hline 5 & 6 \\
\hline 6 & 6 \\
\hline 7 & 6 \\
\hline 8 & 5 \\
\hline 9 & 4 \\
\hline 10 & 3 \\
\hline
\end{tabular}

Table S4. Conformational ensemble population distribution for the top ten most populated distinct structures (clusters) of $\mathrm{PEP}_{\mathrm{Au}}{ }^{\mathrm{M}-\mathrm{ox}, 9}$ (AYSSGAPPM ${ }^{\mathrm{ox}} \mathrm{PPF}$ ) in the unadsorbed state.

\begin{tabular}{|c|c|}
\hline $\begin{array}{c}\text { Cluster } \\
\text { rank }\end{array}$ & $\begin{array}{c}\text { Percentage } \\
\text { population }\end{array}$ \\
\hline 1 & 17 \\
\hline 2 & 7 \\
\hline 3 & 5 \\
\hline 4 & 4 \\
\hline 5 & 4 \\
\hline 6 & 3 \\
\hline 7 & 3 \\
\hline 8 & 3 \\
\hline 9 & 2 \\
\hline 10 & 2 \\
\hline
\end{tabular}


Table S5. Conformational ensemble population distribution for the top ten most populated distinct structures (clusters) of $\mathrm{PEP}_{\mathrm{Au}}{ }^{\mathrm{M}-\mathrm{ox}, 7}$ (AYSSGAM ${ }^{\mathrm{ox}} \mathrm{PPPPF}$ ) in the unadsorbed state.

\begin{tabular}{|c|c|}
\hline $\begin{array}{c}\text { Cluster } \\
\text { rank }\end{array}$ & $\begin{array}{c}\text { Percentage } \\
\text { population }\end{array}$ \\
\hline 1 & 24 \\
\hline 2 & 8 \\
\hline 3 & 7 \\
\hline 4 & 4 \\
\hline 5 & 4 \\
\hline 6 & 4 \\
\hline 7 & 4 \\
\hline 8 & 3 \\
\hline 9 & 2 \\
\hline 10 & 2 \\
\hline
\end{tabular}

Table S6. Conformational ensemble population distribution for the top ten most populated distinct structures (clusters) of $\mathrm{PEP}_{\mathrm{Au}}^{\mathrm{M}-\mathrm{ox}, 11}$ (AYSSGAPPPPM ${ }^{\mathrm{ox}} \mathrm{F}$ ) in the unadsorbed state.

\begin{tabular}{|c|c|}
\hline $\begin{array}{c}\text { Cluster } \\
\text { rank }\end{array}$ & $\begin{array}{c}\text { Percentage } \\
\text { population }\end{array}$ \\
\hline 1 & 22 \\
\hline 2 & 9 \\
\hline 3 & 8 \\
\hline 4 & 7 \\
\hline 5 & 5 \\
\hline 6 & 5 \\
\hline 7 & 4 \\
\hline 8 & 4 \\
\hline 9 & 3 \\
\hline 10 & 3 \\
\hline
\end{tabular}




\section{Cross-cluster similarity analysis}

Table S7. Cross-cluster similarity analysis. The top five most populated clusters for $\mathrm{PEP}_{\mathrm{Au}}{ }^{\mathrm{M}, 9}$ are compared with all clusters generated for $\mathrm{PEP}_{\mathrm{Au}}{ }^{\mathrm{M}-\mathrm{ox}, 9}$ based on the root mean squared deviation (RMSD) of the backbone atom positions, within a cutoff of $0.2 \mathrm{~nm}$ (the same as was used for the clustering analysis). Entries in black designate a cluster match, entries in red signify a near match (with an RMSD within a cutoff of $0.25 \mathrm{~nm}$ ).

\begin{tabular}{|c|c|}
\hline Cluster rank of $\mathrm{PEP}_{\mathrm{Au}}{ }^{\mathrm{M}, 9}$ & Cluster rank of $\mathrm{PEP}_{\mathrm{Au}}{ }^{\mathrm{M}-\mathrm{ox}, 9}$ \\
\hline 0 & 1,5 \\
\hline 1 & $1,3,9$ \\
\hline 2 & 5 \\
\hline 3 & - \\
\hline 4 & 2 \\
\hline
\end{tabular}

Table S8. Cross-cluster similarity analysis. The top five most populated clusters for $\mathrm{PEP}_{\mathrm{Au}}{ }^{\mathrm{M}, 7}$ are compared with all clusters generated for $\mathrm{PEP}_{\mathrm{Au}}{ }^{\mathrm{M}-\mathrm{ox}, 7}$, based on the root mean squared deviation (RMSD) of the backbone atom positions, within a cutoff of $0.2 \mathrm{~nm}$ (the same as was used for the clustering analysis). Entries in black designate a cluster match, entries in red signify a near match (with an RMSD within a cutoff of $0.25 \mathrm{~nm}$ ).

\begin{tabular}{|c|c|}
\hline Cluster rank of $\mathrm{PEP}_{\mathrm{Au}}{ }^{\mathrm{M}, 7}$ & Cluster rank of $\mathrm{PEP}_{\mathrm{Au}}{ }^{\mathrm{M}-\mathrm{ox}, 7}$ \\
\hline 0 & 3,4 \\
\hline 1 & 1,6 \\
\hline 2 & 2,5 \\
\hline 3 & 3,8 \\
\hline 4 & 2,5 \\
\hline
\end{tabular}

Table S9. Cross-cluster similarity analysis. The top five most populated clusters for $\mathrm{PEP}_{\mathrm{Au}}^{\mathrm{M}, 11}$ are compared with all clusters generated for $\mathrm{PEP}_{\mathrm{Au}}{ }^{\mathrm{M}-\mathrm{ox}, 11}$, based on the root mean squared deviation (RMSD) of the backbone atom positions, within a cutoff of $0.2 \mathrm{~nm}$ (the same as was used for the clustering analysis). Entries in black designate a cluster match, entries in red signify a near match (with an RMSD within a cutoff of $0.25 \mathrm{~nm}$ ).

\begin{tabular}{|c|c|}
\hline Cluster rank of $\mathrm{PEP}_{\mathrm{Au}}{ }^{\mathrm{M}, 11}$ & Cluster rank of $\mathrm{PEP}_{\mathrm{Au}}{ }^{\mathrm{M}-\mathrm{ox}, 11}$ \\
\hline 0 & 0 \\
\hline 1 & - \\
\hline 2 & 8 \\
\hline 3 & 0,2 \\
\hline 4 & 4 \\
\hline
\end{tabular}


CD spectroscopy of peptides in the absence of gold

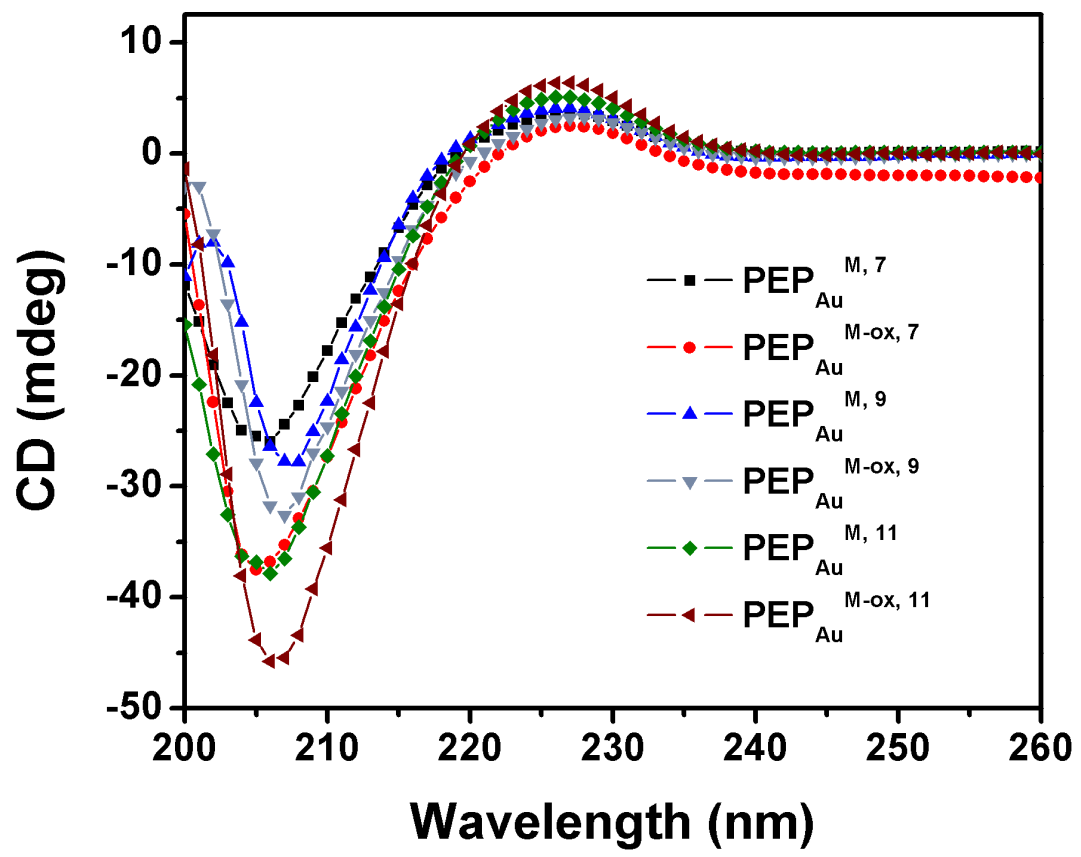

Figure S4. CD spectra of methionine-based variant peptides dissolved in $10 \mathrm{mM}$ HEPES buffer. All peptides exhibit a characteristic PPII signature. 
Table S10. Percentage occupation of the principal regions of secondary structure in a Ramachandran plot, calculated over all frames of the REST MD simulation trajectories for each peptide in the unadsorbed state. Unclassified states are designated as random coil (RC).

\begin{tabular}{|c|c|c|c|c|c|c|c|}
\hline Peptide & $\alpha$ & $\alpha$ & $\beta$ & $\gamma$ & $\gamma$ & PPII & RC \\
\hline PEP $_{\mathrm{Au}}^{\mathrm{M}, 7}$ & 22 & 1 & 14 & 2 & 1 & 55 & 5 \\
\hline $\mathrm{PEP}_{\mathrm{Au}}^{\mathrm{M}, 9}$ & 22 & 1 & 13 & 1 & 1 & 58 & 4 \\
\hline $\mathrm{PEP}_{\mathrm{Au}}^{\mathrm{M}, 11}$ & 9 & 11 & 6 & 2 & 1 & 33 & 37 \\
\hline $\mathrm{PEP}_{\mathrm{Au}}{ }^{\mathrm{M}-\mathrm{ox}, 7}$ & 28 & 3 & 13 & 2 & 1 & 48 & 5 \\
\hline $\mathrm{PEP}_{\mathrm{Au}}{ }^{\mathrm{M}-\mathrm{ox}, 9}$ & 28 & 1 & 14 & 2 & 1 & 52 & 4 \\
\hline $\mathrm{PEP}_{\mathrm{Au}}^{\mathrm{M}-\mathrm{ox}, 11}$ & 6 & 13 & 5 & 4 & 1 & 27 & 44 \\
\hline
\end{tabular}


Additional TEM images of gold nanoparticle superstructures
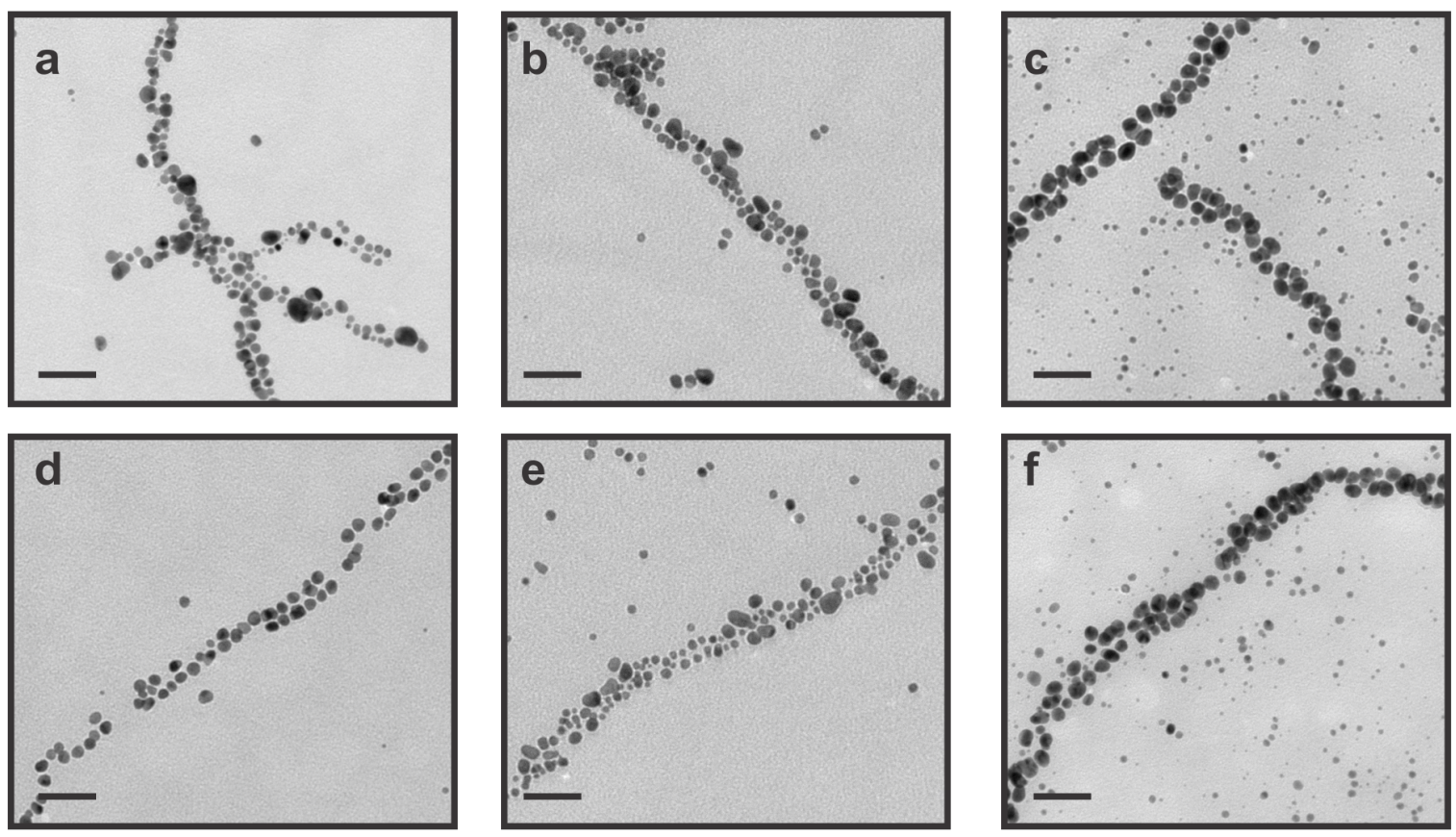

Figure S5. TEM images of AuNP superstructures derived from (a, d) $\mathrm{C}_{18}-\left(\mathrm{PEP}_{\mathrm{Au}}^{\mathrm{M}, 7}\right)_{2},(\mathrm{~b}, \mathrm{e}) \mathrm{C}_{18^{-}}$ $\left(\mathrm{PEP}_{\mathrm{Au}}{ }^{\mathrm{M}, 9}\right)_{2}$, (c, f) $\mathrm{C}_{18}-\left(\mathrm{PEP}_{\mathrm{Au}}^{\mathrm{M}, 11}\right)_{2}$. Scale bar: $50 \mathrm{~nm}$. 


\section{AFM analysis of helical ribbons}
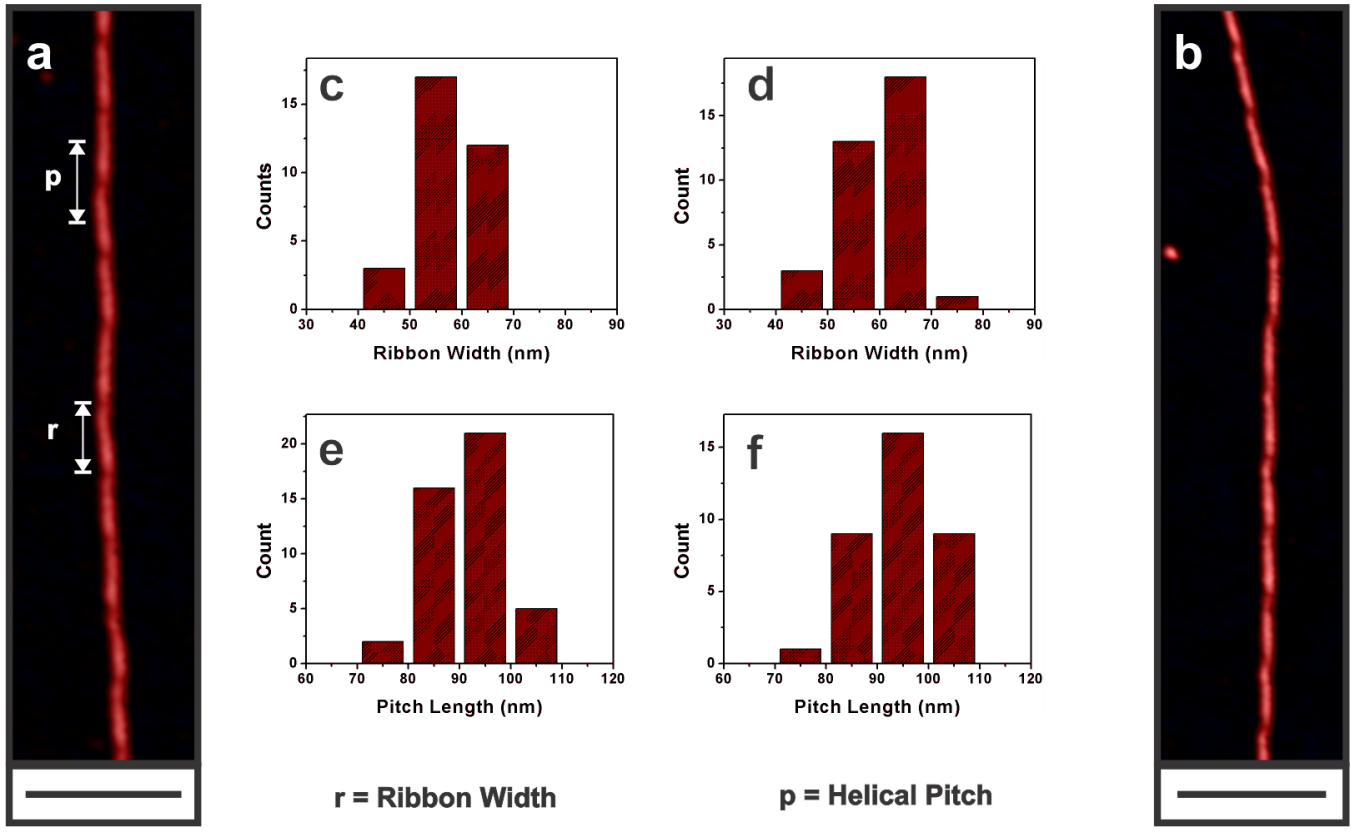

$\mathbf{r}=$ Ribbon Width

$p=$ Helical Pitch

Figure S6. AFM analysis of helical ribbon fibers formed by (a) $\mathrm{C}_{18}-\left(\mathrm{PEP}_{\mathrm{Au}}{ }^{\mathrm{M}-\mathrm{ox}, 7}\right)_{2}$ and (b) $\mathrm{C}_{18^{-}}$ $\left(\mathrm{PEP}_{\mathrm{Au}}{ }^{\mathrm{M}-\mathrm{ox}, 11}\right)_{2}$. (c, d) Ribbon width distribution of helical ribbons derived from $\mathrm{C}_{18}-\left(\mathrm{PEP}_{\mathrm{Au}}{ }^{\mathrm{M}-\mathrm{ox}, 7}\right)_{2}$ and $\mathrm{C}_{18}-\left(\mathrm{PEP}_{\mathrm{Au}}^{\mathrm{M}-\mathrm{ox}, 11}\right)_{2}$, respectively. (e, f) Pitch distribution of helical ribbons derived from $\mathrm{C}_{18^{-}}$ $\left(\mathrm{PEP}_{\mathrm{Au}}^{\mathrm{M}-\mathrm{ox}, 7}\right)_{2}$ and $\mathrm{C}_{18}-\left(\mathrm{PEP}_{\mathrm{Au}}^{\mathrm{M}-\mathrm{ox}, 11}\right)_{2}$, respectively. Scale bar: $200 \mathrm{~nm}$. 
TEM images of unassembled AuNPs formed in the $\mathrm{C}_{18}-\left(\mathrm{PEP}_{\mathrm{Au}}{ }^{\mathrm{M}-\mathrm{ox}}{ }^{7}\right)_{2}$-based synthesis
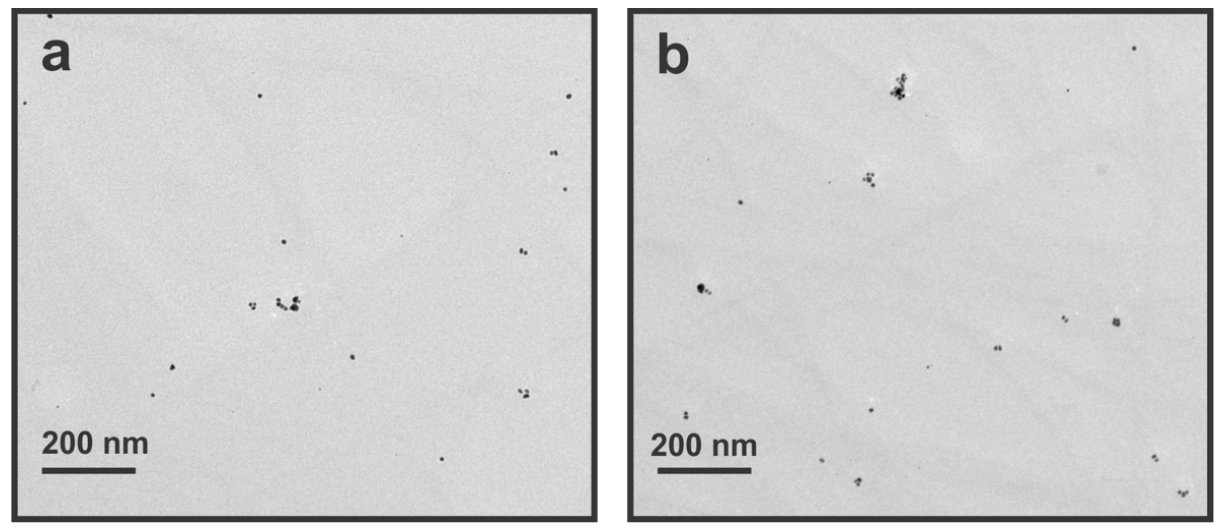

Figure S7. TEM analysis of free unassembled gold nanoparticles formed by $\mathrm{C}_{18}-\left(\mathrm{PEP}_{\mathrm{Au}}^{\mathrm{M}-\mathrm{ox}, 7}\right)_{2}$. 
TEM images of AuNP single-helical superstructures
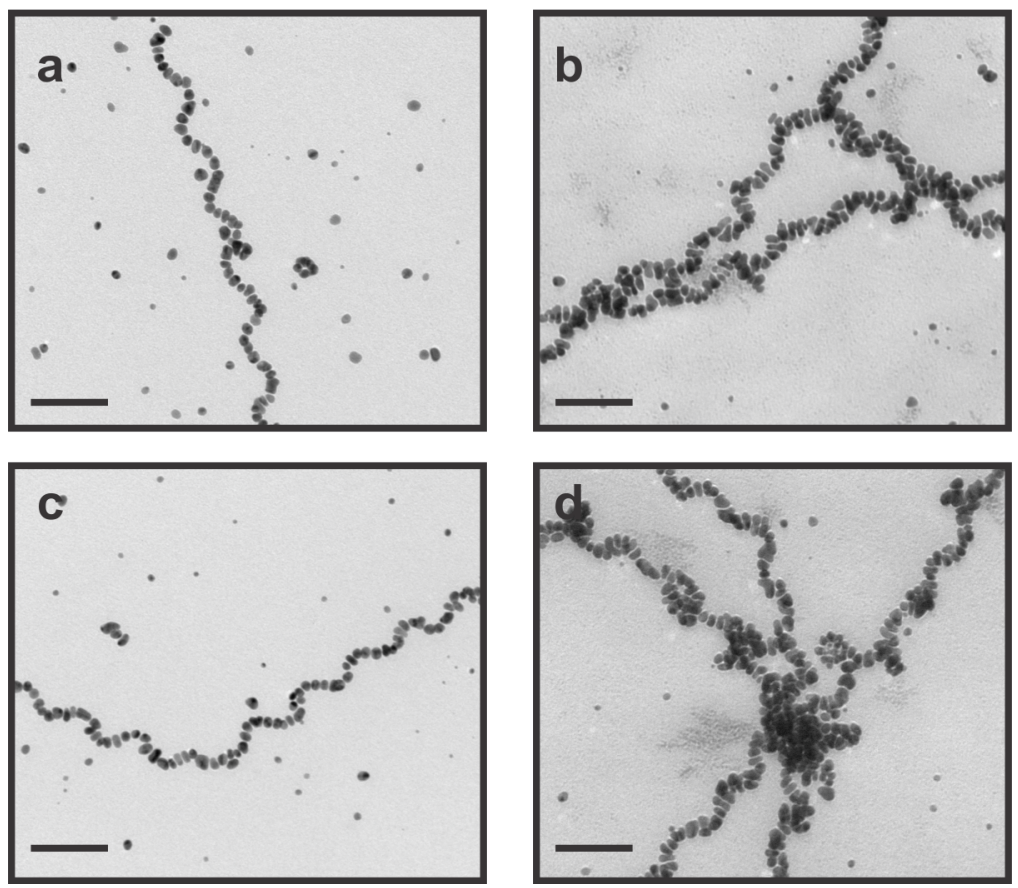

Figure S8. TEM analysis of single-helical superstructures formed by $(\mathrm{a}, \mathrm{c}) \mathrm{C}_{18}-\left(\mathrm{PEP}_{\mathrm{Au}}^{\mathrm{M}-\mathrm{ox}, 9}\right)_{2}$ and (b, d) $\mathrm{C}_{18}-\left(\mathrm{PEP}_{\mathrm{Au}}^{\mathrm{M}-\mathrm{ox}, 11}\right)_{2}$. Scale bar: $100 \mathrm{~nm}$. 


\section{Additional computational methodology}

We performed REST-MD simulations for each of the six peptides $\left(\mathrm{PEP}_{\mathrm{Au}}{ }^{\mathrm{M}, 7}, \mathrm{PEP}_{\mathrm{Au}}{ }^{\mathrm{M}, 9}\right.$, $\mathrm{PEP}_{\mathrm{Au}}{ }^{\mathrm{M}, 11}, \mathrm{PEP}_{\mathrm{Au}}{ }^{\mathrm{M}-o x, 7}, \mathrm{PEP}_{\mathrm{Au}}{ }^{\mathrm{M}-\mathrm{ox}, 9}, \mathrm{PEP}_{\mathrm{Au}}{ }^{\mathrm{M}-\mathrm{ox}, 11}$ ) both in the unadsorbed state and adsorbed at the aqueous $\mathrm{Au}(111)$ interface.

General Simulation Set-up Details: We used an orthorhombic periodic cell and periodic boundary conditions were applied in all three principal directions. All simulations were performed in the Canonical (NVT) ensemble, at a thermal temperature of $300 \mathrm{~K}$, maintained using the Nosé-Hoover thermostat, ${ }^{1,2}$ with a coupling constant of $\tau=0.2$ ps. Newton's equations of motion were solved using an integration time-step of $1 \mathrm{fs}$. Coordinates were saved every 1ps. Long-ranged electrostatic interactions were treated using Particle-mesh Ewald (PME), ${ }^{3}$ with a cut-off at $11 \AA$, whereas a force-switched cut-off, starting at $9 \AA$ and ending at $10 \AA$ was used for the Lennard-Jones non-bonded interactions.

The GolP-CHARMM ${ }^{4}$ force-field was used to model the Au slab. The peptides were described based on the CHARMM22* force-field ${ }^{5,6}$ and water was described using the modified TIP3P $\mathrm{P}^{7,8}$ model. All Au atoms in the slab were held fixed in space during these simulations, with only the Au atom dipoles able to freely rotate. Random initial dipole positions were used throughout. Our recent tests indicate that there is very little difference between binding obtained using a rigid substrate, vs. using a slab where all atoms can move. ${ }^{9}$

Replica Exchange with Solute Tempering Molecular Dynamics (REST-MD) Simulations: Our simulation results comprise output from twelve simulations in total; six simulations for each of the peptides considered in this work, in both the surface-adsorbed and unadsorbed states. For the surface-adsorbed simulations, our system comprised one peptide chain; a Au slab, five atomic layers thick, presenting the Au(111) surface on both slab facets; and $\sim 6000$ TIP3P water molecules. The dimensions of the simulation cell were $\sim 58 \times 61 \times 68 \AA$, with the Au slab placed in the $x, y$ plane. The dimension of the periodic cell perpendicular to the slab plane was adjusted such that the density of liquid water in the center of the space between the slab and its periodic image recovered the target density of bulk liquid water at $300 \mathrm{~K}$ using the modified TIP3P model. For the unadsorbed simulations, the setup was similar except that we used a cubic periodic simulation cell with $\sim 6600$ modified TIP3P water molecules.

We used the Gromacs software package, v5.1.3. ${ }^{10}$ Full technical details of the Terakawa implementation ${ }^{11}$ of REST have been given by us previously. ${ }^{12}$ In our REST simulations, we spanned an 'effective temperature' window of 300-430K, using 16 replicas. The initial configurations for each replica spanned a wide range of conformations and secondary structures. The adsorbate structure for each replica was initially placed within $\sim 5 \AA$ distance from the top surface of the Au slab. The 16 values of lambda used to scale our force-field were:

$\lambda j=0.000,0.057,0.114,0.177,0.240,0.310,0.382,0.458,0.528,0.597,0.692,0.750$, $0.803,0.855,0.930,1.000$. 
Prior to initiation of each REST-MD simulation, the 16 initial configurations were equilibrated at their target potential for $0.5 \mathrm{~ns}$, with no exchange moves attempted during this time. During the REST simulations, the interval between exchange attempts was set to every 1 ps. All production REST simulations were run for a total of $15 \times 10^{6}$ MD steps (15 ns).

REST MD Clustering Analysis: Detailed analysis was carried out on the constantensemble run that corresponded to an effective temperature of $300 \mathrm{~K}$ (replica 0 ; herein referred to as the reference trajectory). We classified the Boltzmann-weighted ensemble of conformations from our reference trajectories into groups of "like structures", on the basis of similarity of their backbone structures. This was accomplished using the Daura clustering algorithm ${ }^{13}$ with a root mean-squared deviation (RMSD) cutoff between the positions all peptide backbone atoms of $2 \AA$. Our extensive experience based on clustering analyses of dodecapeptides informed our identification of this cutoff value. We performed our clustering analysis over the entire $15 \mathrm{~ns}$ trajectory in each case. This analysis yields several principal outputs; the number of clusters (i.e. the number of distinct peptide conformations), the population of each cluster in the ensemble, and the representative structure (i.e. cluster centroid) of each cluster. The population of a given cluster was calculated as the percentage fraction of the number of frames that were assigned membership of that cluster, divided by the total number of frames in the trajectory. The cluster with the largest population corresponds with the most likely structure of the peptide.

For our cross-cluster analysis, we compared the set of cluster centroid structures generated for two different peptides, based on the mathematical similarity of their backbone conformations. We accomplished this by alligning the backbone structure of each cluster centroid of peptide1 against the backbone structure of each cluster centroid of peptide2. Similarity was determined on the basis of the RMSD in backbone atom positions, with a "match" denoted as an RMSD of less than the clustering cutoff ( $2 \AA)$, and a "near match" corresponding to an RMSD of less than $2.5 \AA$. The analysis can identify if two peptides feature a similar set of backbone conformations (secondary structures).

REST MD Contact Residue Analysis: To quantify residue-surface contact for each reference trajectory, we calculated the distance between the topmost layer of the Au surface and each residue in the peptide sequence. For a residue to be determined as in contact with the surface, the residue-surface separation was required to be within a residue-specific distance cut-off. The cut-offs used here have been published elsewhere ${ }^{14}$, along with the corresponding reference site for each residue. For methionine sulfoxide, we used the sulfur atom as the reference site and used the same cut-off that was used for methionine.We calculated the percentage of frames in the reference trajectory for which each residue was found within the contact range of surface-residue separation.

First Principles Calculations: Plane-wave density functional theory calculations were carried out for dimethyl sulfoxide adsorbed onto the $\mathrm{Au}(111)$ surface in vacuo, using Quantum Espresso (version 5.2.0). ${ }^{15}$ For consistency, we followed the same approach that was used to derive the GolP-CHARMM force-field. Three-dimensional periodic boundary conditions were employed using a $3 \times 3 \sqrt{3}$ supercell $(\mathrm{Au}-\mathrm{Au}$ lattice parameter of 2.93 
$\AA^{16}$ ). A gold slab four atomic layers thick was used Calculations were performed using vdW-DF ${ }^{17-19}$ with the revPBE exchange-correlation functional ${ }^{20}$ and ultrasoft pseudopotentials $^{21}$ (based on the PBE exchange-correlation functional ${ }^{22}$ ). Plane wave kinetic energies and electron densities were truncated at 25 and $200 \mathrm{Ry}$, respectively.

The optimal adsorbate-gold geometry was obtained by relaxing the structure of dimethyl sulfoxide when in close proximity to the surface (to a convergence criterion of $0.026 \mathrm{eV} / \AA$ ). We used a vacuum thickness of $10 \AA$ (perpendicular to the Au plane) to minimize interactions between periodic images, and a Monkhorst-Pack $k$-point mesh of $4 \times 4 \times 1$ for the geometry optimization. The interaction energy, $\Delta E_{\text {mol_Au }}$, was calculated using the supermolecule approach, according to:

$$
\Delta E_{m o l \_A u}=E_{m o l \_A u}-E_{m o l}-E_{A u}
$$

where $E_{m o l} A u, E_{m o l}$, and $E_{A u}$ are the total energies of systems describing the small molecule adsorbed at the interface, the adsorbate only, and the gold slab only, respectively. A thicker vacuum layer of $15 \AA$ and a finer Monkhorst-Pack $k$-point mesh of $6 \times 8 \times 1$ was employed in the single-point energy calculation. 


\section{Comparison with Previous Modeling Studies}

There are several previously-reported MD simulation studies of A3 adsorption at the aqueous $\mathrm{Au}(111)$ interface ${ }^{14,23-27}$. All of these studies, using a range of interatomic forcefields, have consistently identified Met9 as a strong gold-binding residue. Furthermore, other strong-binding residues identified by previous studies include Tyr2 and Phe12, also in agreement with our work (Figure 2, main text). Notably, the strong binding character of Met9 in the A3 sequence was also recently confirmed ${ }^{27}$ by both QCM measurement and modeling for a variant of A3 where Met9 was replaced with Ala, resulting in diminished surface contact and a reduced binding free energy $\left(-28.8 \mathrm{~kJ} \mathrm{~mol}^{-1}\right.$, compared with $-31.6 \mathrm{~kJ}$ $\mathrm{mol}^{-1}$ for the original A3 peptide). 


\section{References}

1. Nosé, S. Mol. Phys. 1984, 52, 255.

2. Hoover, W. G. Canonical dynamics: Equilibrium phase-space distributions. Phys. Rev. A 1985, 31, 1695.

3. Darden, T.; York, D.; Pedersen, L. J. Chem. Phys. 1993, 98, 10089.

4. Wright, L.B.; Rodger, P.M.; Corni, S.; Walsh, T.R. J. Chem. Theor. Comput. 2013, 9, 1616.

5. MacKerell, A. D.; et al. J. Phys. Chem. B 1998, 102, 3586.

6. Piana, S.; Lindorff-Larsen, K.; Shaw, D. E. Biophys. J. 2011, 100, 47.

7. Jorgensen, W. L.; Chandrasekhar, J.; Madura, J. D.; Impey, R.W.; Klein, M. L. J. Chem. Phys. 1983, 79, 926.

8. Neria, E.; Fischer, S.; Karplus, M. J. Chem. Phys. 1996, 105, 1902.

9. Wright, L. B.; Freeman, C. L.; Walsh, T. R. Mol. Simulat. 2013, 39, 1093.

10. Abraham, M. J.; Murtola, T.; Schulz, R.; Pall, S; Smith, J.C.; Hess, B.; Lindahl, E. Software X, 2015, 1-2, 19.

11. Terakawa, T.; Kameda, T.; Takada, S. J. Comput. Chem. 2011, 32, 1228.

12. Wright, L.B.; Walsh, T.R. Phys. Chem. Chem. Phys. 2013, 15, 4715.

13. Daura, X.; Gademann, K.; Jaun, B.; Seebach, D.; van Gunsteren, W. F.; Mark, A. E. Angew. Chem. Int. Ed.1999, 38, 236.

14. Tang, Z.; Palafox-Hernandez, J. P.; Law, W.-C.; Hughes, Z. E.; Swihart, M. T.; Prasad, P. N.; Knecht, M. R.; Walsh, T. R. ACS Nano 2013, 7, 9632.

15. Giannozzi, P.; Baroni, S.; Bonini, N.; Calandra, M.; Car, R.; Cavazzoni, C.; Ceresoli, D.; Chiarotti, G. L.; Cococcioni, M.; Dabo, I.; et al. J. Phys.: Condens. Matter 2009, 21, 395502.

16. Rosa, M.; Corni, S.; Di Felice, R. J. Phys. Chem. C 2012, 116, 21366.

17. Dion, M.; Rydberg, H.; Schroder, E.; Langreth, D. C.; Lundqvist, B. I. Phys. Rev. Lett. 2004, 92, 246401.

18. Thonhauser, T.; Cooper, V. R.; Li, S.; Puzder, A.; Hyldgaard, P.; Langreth, D. C. Phys. Rev. B 2007, 76, 125112.

19. Roman-Perez, G.; Soler, J. M. Phys. Rev. Lett. 2009, 103, 096102.

20. Hammer, B.; Hansen, L. B.; Norskov, J. K. Phys. Rev. B 1999, $59,7413$.

21. Vanderbilt, D. Phys. Rev. B 1990, 41, 7892.

22. Perdew, J. P.; Burke, K.; Ernzerhof, M. Phys. Rev. Lett. 1996, 77, 3865.

23. Heinz, H.; Farmer, B. L.; Pandey, R. B.; Slocik, J. M.; Patnaik, S. S.; Soumya, S.; Pachter, R.; Naik, R. R. J. Am. Chem. Soc., 2009, 131, 9704.

24. Feng, J.; Slocik, J. M.; Sarikaya, M.; Naik, R. R.; Farmer, B. L.; Heinz, H. Small, 2012, 8, 1049.

25. Yu, J.; Becker, M. L.; Carri, G. A. Langmuir, 2012, 28, 1408.

26. Bedford, N. M.; Hughes, Z. E.; Tang, Z.; Li, Y.; Briggs, B. D.; Ren, Y.; Swihart, M. T.; Petkov, V. G.; Naik, R. R.; Knecht, M. R.; Walsh, T. R. J. Am. Chem. Soc. 2016, 138,540 .

27. Nguyen, M. A.; Hughes, Z. E.; Liu, Y.; Li, Y.; Swihart, M. T.; Knecht, M. R.; Walsh, T. R. J. Phys. Chem. C, 2018, 122, 11532. 